\title{
Care for perinatal illness in rural Nepal: a descriptive study with
} cross-sectional and qualitative components

\author{
Natasha Mesko1, David Osrin ${ }^{1}$, Suresh Tamang2, Bhim P Shrestha ${ }^{2}$, \\ Dharma S Manandhar ${ }^{2}$, Madan Manandhar ${ }^{2}$, Hilary Standing ${ }^{3}$ and \\ Anthony $\mathrm{M}$ de L Costello*1
}

\begin{abstract}
Address: ${ }^{1}$ International Perinatal Care Unit, Institute of Child Health, University College, London, UK, ${ }^{2}$ Mother Infant Research Activities [MIRA] GPO Box 921, Kathmandu, Nepal and 3Institute of Development Studies, Falmer, Brighton, Sussex BN1 9RH, UK

Email: Natasha Mesko - n_mesko@hotmail.com; David Osrin - davido@wlink.com.np; Suresh Tamang - mira@vianet.com.np; Bhim P Shrestha - mira@vianet.com.np; Dharma S Manandhar - dsm@healthnet.org.np; Madan Manandhar - m.manandhar@info.com.np; Hilary Standing - H.Standing@ids.ac.uk; Anthony M de L Costello* - a.costello@ich.ucl.ac.uk

* Corresponding author
\end{abstract}

\section{Published: 2I August 2003}

BMC International Health and Human Rights 2003, 3:3
Received: 12 February 2003

Accepted: 21 August 2003

This article is available from: http://www.biomedcentral.com/l472-698X/3/3

(C) 2003 Mesko et al; licensee BioMed Central Ltd. This is an Open Access article: verbatim copying and redistribution of this article are permitted in all media for any purpose, provided this notice is preserved along with the article's original URL.

\begin{abstract}
Background: Maternal, perinatal and neonatal mortality rates remain high in rural areas of developing countries. Most deliveries take place at home and care-seeking behaviour is often delayed. We report on a combined quantitative and qualitative study of care seeking obstacles and practices relating to perinatal illness in rural Makwanpur district, Nepal, with particular emphasis on consultation strategies.
\end{abstract}

Methods: The analysis included a survey of 8798 women who reported a birth in the previous two years [of whom 3557 reported illness in their pregnancy], on 30 case studies of perinatal morbidity and mortality, and on 43 focus group discussions with mothers, other family members and health workers.

Results: Early pregnancy was often concealed, preparation for birth was minimal and trained attendance at birth was uncommon. Family members were favoured attendants, particularly mothers-in-law. The most common recalled maternal complications were prolonged labour, postpartum haemorrhage and retained placenta. Neonatal death, though less definable, was often associated with cessation of suckling and shortness of breath. Many home-based care practices for maternal and neonatal illness were described. Self-medication was common.

There were delays in recognising and acting on danger signs, and in seeking care beyond the household, in which the cultural requirement for maternal seclusion, and the perceived expense of care, played a part. Of the 760 women who sought care at a government facility, $70 \%$ took more than 12 hours from the decision to seek help to actual consultation. Consultation was primarily with traditional healers, who were key actors in the ascription of causation. Use of the government primary health care system was limited: the most common source of allopathic care was the district hospital. 
Conclusions: Major obstacles to seeking care were: a limited capacity to recognise danger signs; the need to watch and wait; and an overwhelming preference to treat illness within the community. Safer motherhood and newborn care programmes in rural communities, must address both community and health facility care to have an impact on morbidity and mortality. The roles of community actors such as mothers-in-law, husbands, local healers and pharmacies, and increased access to properly trained birth attendants need to be addressed if delays in reaching health facilities are to be shortened.

\section{Background}

Bachha paaune kahile kahile

Kokro banaaune ahile

Only build the cradle when the baby is born

For mothers and newborn infants in Nepal, perinatal illness usually begins and ends at home. The current perinatal mortality rate is 47 per thousand births and the neonatal mortality rate 39 per thousand live births [1]. About $90 \%$ of births take place at home [1,2], and the establishment of local health care facilities has not necessarily led to their usage [3]. Less than half of women receive any antenatal care, and less than $15 \%$ of births are attended by a trained service provider [1]. The reasons for this are economic, geographic, cultural and institutional [4-6]. Salient institutional problems include absenteeism, minimal staff support, lack of medicines and equipment, and deficiencies in the referral system.

Government health services are not, however, the whole story. When illness occurs, a range of local care providers is available. Choices are made within a network of traditional and allopathic options that also encompasses perceived costs, geographical and climatic constraints, the time of day, the type of illness, ethnic and religious concerns, and chance. We are currently conducting a study on the impact of a community-based participatory intervention to improve essential newborn care, working with women's groups [7]. The study is a cluster randomised trial involving 24 Village Development Committees [standard rural geopolitical units] of Makwanpur District, south-central Nepal.

\section{Objectives}

Germane to our intervention study is an understanding of community perceptions of illness during maternity, and responses to those perceptions. The objectives of the present study were as follows: to quantify perceived illness; to examine home care practices for illness; to quantify care seeking practices for illness; and to examine the choice of care.

\section{Methods \\ Setting}

Nepal is a nation of 23.2 million in which poverty is the norm. Per capita Gross Domestic Product [GDP] is 240 US dollars [8] and $14 \%$ of the population earn less than a dollar a day [9]. 38\% of GDP comes from agriculture [8], a falling share given that $80 \%$ of the population are still primarily engaged in agricultural activities [10]. Over 100 castes, ethnic groups and subgroups inhabit a landscape covering three topographic belts, high Himalaya, middle hills and southern plains. Demographic indices reflect the attendant poverty, limited communications and infrastructure. Life expectancy is now 61 years [only recently has the female figure caught up with that of males], female adult literacy is $43 \%[11,12]$ and the total fertility rate is 4.1 [2.1 in urban areas and 4.4 in rural] [1].

Nepal introduced and integrated its primary health care programmes from the early 1980 s. The model is familiar, with tertiary hospitals at the centre, zonal and district hospitals at nodal points in the periphery, and a hierarchy of primary health centres, health posts and sub-health posts reaching down into the community.

Makwanpur district covers about $2500 \mathrm{sq} \mathrm{km}$ to the south of Kathmandu. It has a population of almost 400000 , mostly engaged in subsistence agriculture. Makwanpur includes both hills and plains, has two main motorable roads and is divided into 42 Village Development Committees and a municipality. The largest ethnic bloc is Tamang, a Tibeto-Burman, predominantly Buddhist group [ $46 \%$, followed by a Brahmin and Chhetri group of Indo-Aryan origin [25\%], and then at least 15 other groups. A 24-bed district hospital in the municipality of Hetauda, four primary health centres and 40 health posts or sub-health posts serve the district. There are approximately 500 deliveries per year in the hospital, which provides facilities for blood transfusion but not for caesarian section.

\section{Study design}

The study had two components, quantitative and qualitative. The quantitative component employed a cross-sectional survey of recalled events during previous pregnancies. The qualitative component employed a 
series of morbidity and mortality case studies based on semistructured interviews, and a series of community focus group discussions on the same issues. The survey and qualitative study were carried out concurrently but wholly independently. The survey was carried out in the 24 Village Development Committees - 12 intervention and 12 control - of the greater study. The case studies and focus group discussions were carried out in six Village Development Committees. For methodological reasons, transfer of information from the survey to the qualitative research team was not permitted.

\section{Data collection and analysis}

\section{Survey questionnaire}

We have described the collection of quantitative data elsewhere [13]. Briefly, all married women of reproductive age [15-49 years] residing in the study area were identified, invited to participate and interviewed via a structured questionnaire. A woman was classified as a married woman of reproductive age and entered into the closed cohort if her age was between 15 and 49 completed years on 15 June 2000, if her husband was alive at enrolment, and if her husband either lived with her or made visits that allowed for the possibility of conception within the study period.

The questionnaire was developed through 11 cycles of piloting, evaluation, and repeat piloting. The 44 field interviewers had been involved in questionnaire development for at least three cycles, and were permanent team members with eight months of training and experience. Data were collected between March and November 2001. Interviewers were supported by nine field coordinators, a senior officer and a data auditor, who checked questionnaires at source, at field centres and at the central office. A tenth of interviews were observed by supervisory team members.

We entered data into a relational database management system in Microsoft SQL server 7.0 [Microsoft Corporation, USA], which incorporated intrafield and interfield validation constraints. For this study, we examined questions about maternal illness and care seeking practices during the preceding pregnancy. We examined frequencies and outliers through structured queries in the database environment. We examined proportions in intercooled Stata 7.0 [Stata Corporation, USA]. We have rounded percentages to integers for presentation.

\section{Case studies}

From a sampling frame of the 12 intervention Village Development Committees in which our facilitation team were active, six were purposively sampled to be as heterogeneous as possible with respect to topography and demography. To begin with, facilitators active in these six areas sought information on women who had experienced problems in pregnancies within the previous two months, particularly serious illness or death. Identification of such women over a two month period was followed by a series of case studies, conducted from May to July 2000 . We already had information on normal pregnancy communicated through a series of 51 focus group discussions. 24 of these dealt with the language of pregnancy and the puerperium, and 27 with perinatal care practices [14]. Each case study developed from a meeting with a key informant, either a mother or a close relative if she had died as a result of her illness. In the latter case, respondents were chosen from close family members or friends who had had the most contact with a woman around the time of her death. If the key informant gave her permission, a semistructured interview was carried out. The interview began with a period in which the informant spoke her mind, followed by a series of probes that led to more discussion. The results of this primary interview guided the subsequent selection of other informants for the index case. Each case study comprised between two and four interviews. The illness case studies represented periods of illness in the past two months, neonatal/stillbirths in the past two years, and the period of recall for maternal deaths was five years, in order to capture enough cases [half of the maternal deaths were within two years].

\section{Focus group discussions}

The results of the case studies were fed into the design of a series of focus group discussions, carried out from August to October 2000. Issues that had arisen were raised in discussion and were used as triggers for further ideas. Focus groups were purposively sampled. Each group was made up of participants from a single ethnic bloc and a single gender. During the discussion, facilitators drew pictorial timelines to mark the stages of early and late pregnancy, birth and the postpartum period. The timelines were used to understand the sequential flow of perinatal events and as a focus for discussion. The focus group discussions aimed to generate a degree of community consensus about illness, consequent health care seeking behaviour and decision making.

Tools and methodology for the qualitative components of the study were locally developed and pretested in workshops and in the field. Data were recorded by note-taking and tape-recording, for which permission was given in all cases. Each team member also maintained a diary in which she recorded her personal observations and informal conversations. Raw data were given specific reference codes. A random sample was translated into english by an independent third party and the remaining data by the principal investigators. The data were broken into units 
Table I: Participants in the three components of the study, with selected demographic indicators

\begin{tabular}{|c|c|c|c|c|c|c|c|}
\hline & & & & Ethnic group & & & \\
\hline & Tamang [\%] & $\begin{array}{l}\text { Brahmin- } \\
\text { Chhetri [\%] }\end{array}$ & $\begin{array}{l}\text { Artisanal } \\
\text { group [\%] }\end{array}$ & Newar [\%] & Magar [\%] & Gurung [\%] & Total \\
\hline Quantitative study & & & & & & & \\
\hline Previous births & 5982 & 1615 & 476 & 244 & 407 & 74 & 8798 \\
\hline $\begin{array}{l}\text { Recalled significant illness at any } \\
\text { time during maternity }\end{array}$ & $2476[4 I]$ & $640[40]$ & $208[44]$ & $65[27]$ & $134[33]$ & $34[46]$ & $3557[40]$ \\
\hline Case studies & 15 & 9 & 3 & 1 & 1 & I & 30 \\
\hline Focus groups & & & & & & & \\
\hline With women & 4 & 4 & 5 & 4 & 3 & 3 & 23 \\
\hline With men & 4 & 3 & 4 & 3 & 3 & 3 & 20 \\
\hline $\begin{array}{l}\text { Selected demographic } \\
\text { indicators }\end{array}$ & & & & & & & \\
\hline Maternal age & & & & & & & \\
\hline Under 20 & $708[12]$ & $257[16]$ & 91 [19] & $35[14]$ & $45[\mathrm{II}]$ & $10[13]$ & $1 \mid 46[13]$ \\
\hline $20-29$ & $3252[54]$ & $1093[68]$ & 271 [57] & $161[66]$ & $242[59]$ & $39[53]$ & $5058[58]$ \\
\hline $30-39$ & $1655[28]$ & $222[14]$ & $104[22]$ & $4 \mid[17]$ & $101[25]$ & $19[26]$ & $2142[24]$ \\
\hline 40 and over & $367[6]$ & $43[2]$ & $10[2]$ & $7[3]$ & $19[5]$ & $6[8]$ & $452[5]$ \\
\hline Schooling & & & & & & & \\
\hline None & $5371[90]$ & $768[47]$ & $387[81]$ & 154 [63] & 301 [74] & 54 [73] & $7035[80]$ \\
\hline Up to class 5 & $504[8]$ & $415[26]$ & $68[14]$ & $48[20]$ & $71[17]$ & $17[23]$ & $1123[13]$ \\
\hline Above class 5 & $107[2]$ & $432[27]$ & $21[5]$ & $42[17]$ & $35[9]$ & $3[4]$ & $640[7]$ \\
\hline Appliance score & & & & & & & \\
\hline $\begin{array}{l}\text { 0: None of the possessions } \\
\text { below }\end{array}$ & $3620[61]$ & $552[34]$ & $233[49]$ & $74[30]$ & $197[48]$ & $44[60]$ & 4720 [54] \\
\hline $\begin{array}{l}\text { I: Wall clock, radio, iron, } \\
\text { bicycle }\end{array}$ & $1862[3 \mid]$ & $602[37]$ & $163[34]$ & $82[34]$ & $127[3 \mid]$ & $24[32]$ & 2860 [32] \\
\hline $\begin{array}{l}\text { 2: Hand tractor, sewing } \\
\text { machine, camera, cassette } \\
\text { player, fan }\end{array}$ & $298[5]$ & $195[12]$ & $60[13]$ & $27[11]$ & $43[11]$ & $3[4]$ & $626[7]$ \\
\hline $\begin{array}{l}\text { 3: Any motor vehicle, } \\
\text { television, refrigerator }\end{array}$ & $202[3]$ & $266[17]$ & $20[4]$ & $61[25]$ & $40[10]$ & $3[4]$ & $592[7]$ \\
\hline
\end{tabular}

for analysis and each unit was categorised. Finally, we sorted emergent patterns and processes into themes [15].

\section{Ethical approval}

The study received ethical clearance from the Nepal Health Research Council, His Majesty's Government Ministry of Health, Nepal and the Institute of Child Health and the Hospital for Sick Children, Great Ormond Street, London. Permission was granted by each Village Development Committee chairperson and informed verbal consent was obtained from all participants.

\section{Results}

Table 1 summarises the numbers involved in the study. 25 702 women received the survey questionnaire, of whom 24295 had given birth at least once. Because of concerns about the validity of recall over longer periods, and because of the likelihood that practices have changed over time, we have limited our analysis to births within the two years before the start of the study [23rd March 1999 23rd March 2001]. For compatibility, we have included only the ethnic groups involved in the qualitative study. The analysis is therefore based on the responses of 8798 women. There were 30 case studies and 43 focus group discussions. The case studies included eight maternal deaths, two instances of maternal illness, ten neonatal deaths, two instances of neonatal illness and eight stillbirths. Three of the stillbirths were described as macerated and the remaining five were fresh. Three of the neonatal deaths and one of the stillbirths occurred in association with maternal death. In both components of the study, similar patterns of care were described across ethnic groups.

\section{Maternity care}

Concealment of pregnancy, particularly in the first months, was the norm. Women tended to work until the first signs of labour began, and there were proscriptions on behaviour. Preparation for birth was limited. Specific foodstuffs might be collected and stored in advance, but extensive preparation was seen as tantamount to tempting fate. In respondents' view, events during pregnancy were 
Table 2: Delivery care and consultation findings from the survey questionnaire

\begin{tabular}{|c|c|}
\hline Delivery care & Frequency [\%] \\
\hline \multicolumn{2}{|l|}{ Place of delivery $[\mathrm{n}=8798]$} \\
\hline Home & 8238 [94] \\
\hline Hospital & $435[5]$ \\
\hline \multicolumn{2}{|l|}{ Birth attendant* [n-8798] } \\
\hline Mother-in-law & $3476[40]$ \\
\hline $\begin{array}{l}\text { Doctor, nurse, auxiliary nurse } \\
\text { midwife, health assistant }\end{array}$ & $563[6]$ \\
\hline Traditional birth attendant & $440[5]$ \\
\hline No attendant at all & $1030[12]$ \\
\hline \multicolumn{2}{|l|}{ Consultation for recalled illness } \\
\hline \multicolumn{2}{|l|}{ Place of consultation* [ $\mathrm{n}=3557]$} \\
\hline Traditional healer & $2748[77]$ \\
\hline District hospital & $353[10]$ \\
\hline Primary Health Centre & $132[4]$ \\
\hline Health Post & $176[5]$ \\
\hline Sub-Health Post & 138 [4] \\
\hline $\begin{array}{l}\text { Any government primary } \\
\text { health care institution }\end{array}$ & $443[12]$ \\
\hline $\begin{array}{l}\text { Any government health care } \\
\text { institution }\end{array}$ & $760[21]$ \\
\hline Private clinic & $|5|[4]$ \\
\hline Medicine shop & $115[3]$ \\
\hline \multicolumn{2}{|l|}{$\begin{array}{l}\text { Time from onset of illness to any } \\
\text { treatment }[n=3557]\end{array}$} \\
\hline$>6$ hours & $1108[31]$ \\
\hline$>24$ hours & 906 [25] \\
\hline$>48$ hours & $706[20]$ \\
\hline \multicolumn{2}{|l|}{$\begin{array}{l}\text { Time from onset of illness to } \\
\text { health facility consultation [ } n= \\
760]\end{array}$} \\
\hline$>12$ hours & $531[70]$ \\
\hline$>24$ hours & $454[60]$ \\
\hline$>48$ hours & 361 [48] \\
\hline \multicolumn{2}{|l|}{ Maternal medication $[\mathrm{n}=3557]$} \\
\hline Allopathic & $1087[31]$ \\
\hline Traditional & $354[10]$ \\
\hline Allopathic and traditional & $96[3]$ \\
\hline
\end{tabular}

*These figures allow the possibility of multiple attendants or consultations, which means that they do not sum to the denominator. This has been taken into account in the presentation of grouped frequencies.

intimately connected with problems during delivery and the puerperium.

Table 2 summarises delivery care findings from the survey questionnaire. $94 \%$ of women gave birth at home or in the environs of the home. Only five percent delivered at a hospital, and none did so at a primary health care facility. A woman's commonest birth attendant was her motherin-law [40\%]. Six percent of women were assisted by a doctor, nurse, auxiliary nurse midwife, or health assistant. Traditional birth attendants assisted in only five percent of deliveries, and $12 \%$ of women gave birth entirely alone.
Table 3: Maternal illness findings from the survey questionnaire

\begin{tabular}{|c|c|}
\hline Illness & $\begin{array}{r}\text { Frequency [\%] } N=8798 \text { births } \\
\text { within past two years [100\%] }\end{array}$ \\
\hline $\begin{array}{l}\text { Recalled significant illness at any } \\
\text { time during maternity }\end{array}$ & 3557 [40] \\
\hline \multicolumn{2}{|l|}{ Antenatal events } \\
\hline \multicolumn{2}{|l|}{ Vaginal bleeding } \\
\hline Any bleeding & $445[5]]$ \\
\hline Soaked clothes, bed or floor & $382[4]$ \\
\hline \multicolumn{2}{|l|}{ Signs of pre-eclampsia } \\
\hline Swollen legs + face & 2587 [29] \\
\hline Swollen face + blurred vision & $2189[25]$ \\
\hline $\begin{array}{l}\text { Swollen face + blurred vision + } \\
\text { convulsion }\end{array}$ & $999[11]$ \\
\hline Fever for more than one day & 2018 [23] \\
\hline $\begin{array}{l}\text { Vaginal discharge for more than } \\
\text { one day }\end{array}$ & $1189[14]$ \\
\hline \multicolumn{2}{|l|}{ Intrapartum events } \\
\hline \multicolumn{2}{|l|}{ Prolonged labour } \\
\hline$>12$ hours & $3623[4 I]$ \\
\hline$>24$ hours & $1968[22]$ \\
\hline$>48$ hours & $1089[12]$ \\
\hline \multicolumn{2}{|l|}{ Retained placenta } \\
\hline$>$ I hour & 718 [8] \\
\hline$>6$ hours & $203[2]$ \\
\hline Placenta complete on delivery & 8711 [99] \\
\hline \multicolumn{2}{|l|}{ Postpartum events } \\
\hline $\begin{array}{l}\text { Vaginal bleeding which soaked } \\
\text { clothes, bed or floor }\end{array}$ & $240 \mid$ [27] \\
\hline Fever for more than one day & $1352[15]$ \\
\hline $\begin{array}{l}\text { Vaginal discharge for more than } \\
\text { one day }\end{array}$ & $1155[13]$ \\
\hline
\end{tabular}

The qualitative studies supported these findings. 'Traditional' birth attendants were not seen as having a traditional role in the locality, were rarely called to attend births and tended to be consulted only for emergencies.

\section{Perceived illness}

The survey questionnaire asked about illness in the following four categories: vaginal bleeding, signs of possible pre-eclampsia and eclampsia, fever, and vaginal discharge. 3557 women had experienced one of these in their last pregnancy [40\%]. Responses are summarised in Table 3 . Five percent of women recalled antepartum vaginal bleeding. Since blood pressure had not usually been measured, we attempted to describe hypertensive disease of pregnancy using a constellation of swollen legs, swollen face, blurred vision and convulsions. These are difficult to assess through recall, particularly where there are variations in perception of their definitions. Fever [23\% antepartum and $15 \%$ postpartum] and vaginal discharge [14\% antepartum and $13 \%$ postpartum] were commonly recalled. $22 \%$ of labours were recalled as having lasted longer than 24 hours and in eight percent the placenta 
Table 4: Symptoms and signs recalled by respondents in case studies

\begin{tabular}{|c|c|c|c|c|c|c|c|c|}
\hline Maternal deaths & Case I & Case 2 & Case 3 & Case 4 & Case 5 & Case 6 & Case 7 & Case 8 \\
\hline Retained placenta & $\checkmark$ & $\checkmark$ & $\checkmark$ & $\checkmark$ & $\checkmark$ & & & $\checkmark$ \\
\hline Postpartum haemorrhage & & & $\checkmark$ & $\checkmark$ & $\checkmark$ & & & $\checkmark$ \\
\hline Prolonged labour & & & & $\checkmark$ & $\checkmark$ & & & \\
\hline Fainting during pregnancy & & & & & & $\checkmark$ & & \\
\hline Jaundice & & & & & & $\checkmark$ & & \\
\hline Twin pregnancy & & & & & & & $\checkmark$ & \\
\hline Neonatal deaths a & Case I & Case 2 & Case 3 & Case 4 & Case 5 & Case 6 & Case 7 & Case 8 \\
\hline Suckling stopped & $\checkmark$ & $\checkmark$ & $\checkmark$ & & $\checkmark$ & $\checkmark$ & $\checkmark$ & $\checkmark$ \\
\hline Shortness of breath & $\checkmark$ & $\checkmark$ & $\checkmark$ & & & $\checkmark$ & $\checkmark$ & \\
\hline Yellow colour & & & $\checkmark$ & & & & & \\
\hline Fever & & & $\checkmark$ & & & & & \\
\hline No cry & & & & $\checkmark$ & & & & \\
\hline Blue colour & & & & & & & $\checkmark$ & \\
\hline Time of death & 13 days & 2 hours & 12 days & 5 mins & 15 days & 30 mins & 14 days & 5 days \\
\hline
\end{tabular}

a Two case studies of neonatal deaths have been omitted from this table, since they were felt to be exceptional. In one case, the baby died in hospital after operative delivery. In the other, preterm twins died shortly after birth.

had taken more than an hour to be delivered. A quarter of women recalled severe postpartum vaginal bleeding [27\%].

The major illnesses discussed in the case studies are summarised in Table 4 . The survey questionnaire did not examine neonatal death - we are addressing it prospectively - but the commonest symptoms associated with it in the case studies were cessation of suckling and shortness of breath. In general, however, we found it difficult to identify neonatal complications from key informant interviews because descriptions of symptoms were not clear. In the focus groups on newborn infant health, women described more problems than men. Key neonatal problems included a weak cry, breathing difficulties, poor feeding, feeling cold to the touch, looking very small, and looking yellow.

\section{Home care practices for illness}

The focus group discussions provided some examples of home care practices for specific problems, summarised in Tables 5 and 6. Specific aspects of home care for illness were, however, not prominent in the discussions. Care within the home was rarely provided by men, since menstruation and childbirth are considered female domains. In the few cases where a man was present he tended to be the husband within a nuclear family. For those practices that were discussed, physiological concepts were often explanatory. One example is a mother's avoidance of certain foods when an infant is feverish because of the relationship between her diet and the quality of her breastmilk [16]. A second is the belief in a linkage between the uterus, stomach and heart [17-19]. If the umbilical cord is cut before the placenta has been deliv- ered, it may rise to the mother's heart and kill her. Hence the practice of weighting the cut cord by tying a spade to its end: in one case study the spade came loose and the cord disappeared inside the mother. Respondents believed that this was why she subsequently died.

\section{Care seeking practices for illness}

The survey questionnaire attempted to quantify care seeking practices outside the home [Table 2]. Three-quarters of women who recalled an illness consulted a traditional healer [Dhami Jhankri or Bombo], a finding adequately supported by the qualitative information. A traditional healer was the first care provider outside the household in all the case studies of neonatal deaths. The healer characteristically identifies the causes of illness and so is rarely bypassed in the pursuit of a cure. A hierarchy of choice holds for traditional healers. A healer who is a friend or relative, and of one's own ethnic group, is called first to perform a ceremony. If the condition worsens, a specialist's services are solicited and a longer and more expensive ceremony may be performed. Different illnesses have different characteristics and are treated accordingly. The traditional healer may even suggest the day on which to seek help outside the community.

The situations in which a traditional birth attendant was called were directly related to difficulties in labour, an area in which her skills were seen as appropriate. Some respondents suggested that the perceived inadequacies of the original selection process for traditional birth attendants had knock-on effects in terms of their popularity. "We inform them of the birth but they don't come; this is because of politics...". 
Table 5: Home care practices for maternal problems suggested in focus group discussions

\begin{tabular}{|c|c|c|}
\hline Maternal problem & Dietary remedy & Other practices \\
\hline Antepartum haemorrhage & Meat, milk and eggs. & \\
\hline Prolonged labour & $\begin{array}{l}\text { Hot sugar water, hot milk } \\
\text { and eggs. }\end{array}$ & Hot oil massage with hot compression to woman's lower back. \\
\hline \multirow[t]{7}{*}{ Retained placenta } & $\begin{array}{l}\text { Water from a winnowing } \\
\text { mat. }\end{array}$ & Water or alcohol poured from one cup to another. \\
\hline & Eggs, milk and hot foods & Oil massage to woman's head and abdomen. \\
\hline & & $\begin{array}{l}\text { Abdomen wrapped tightly with large cloth. A root tied around abdomen or put into } \\
\text { cloth. }\end{array}$ \\
\hline & & Woman's hair thrust into her mouth to induce vomiting. \\
\hline & & Talisman placed around woman's neck. \\
\hline & & $\begin{array}{l}\text { Train ticket bound to woman's abdomen. Cord cut and weighted with object such as } \\
\text { spade. }\end{array}$ \\
\hline & & Woman must remain awake. \\
\hline Postpartum haemorrhage & $\begin{array}{l}\text { Hot, spicy soup, oil and } \\
\text { honey. }\end{array}$ & Woman kept warm and hot compression applied. \\
\hline $\begin{array}{l}\text { Postpartum swelling of the } \\
\text { body }\end{array}$ & & $\begin{array}{l}\text { Branches of particular plant placed on top of embers of fire, then layer of old clothes. } \\
\text { Mother lies on top of this, covered by quilt. She must sweat. She is dried and must stay } \\
\text { in the sun. Oil massage and hot compression then performed. }\end{array}$ \\
\hline Postpartum abdominal pain & Oil and honey. & Hot stone wrapped in old clothes placed on woman's abdomen. \\
\hline \multirow[t]{2}{*}{ Poor breast milk supply } & Hot, spicy soup. & Breasts massaged with warm water. \\
\hline & $\begin{array}{l}\text { For the baby: clarified } \\
\text { butter to moisten the } \\
\text { mouth; milk from livestock } \\
\text { or tin; wet nursing; flour } \\
\text { and water porridge. }\end{array}$ & \\
\hline Swollen breast & & Breast heated by bathing in hot water and milk gently squeezed out. \\
\hline
\end{tabular}

Table 6: Home care practices for neonatal problems suggested in focus group discussions

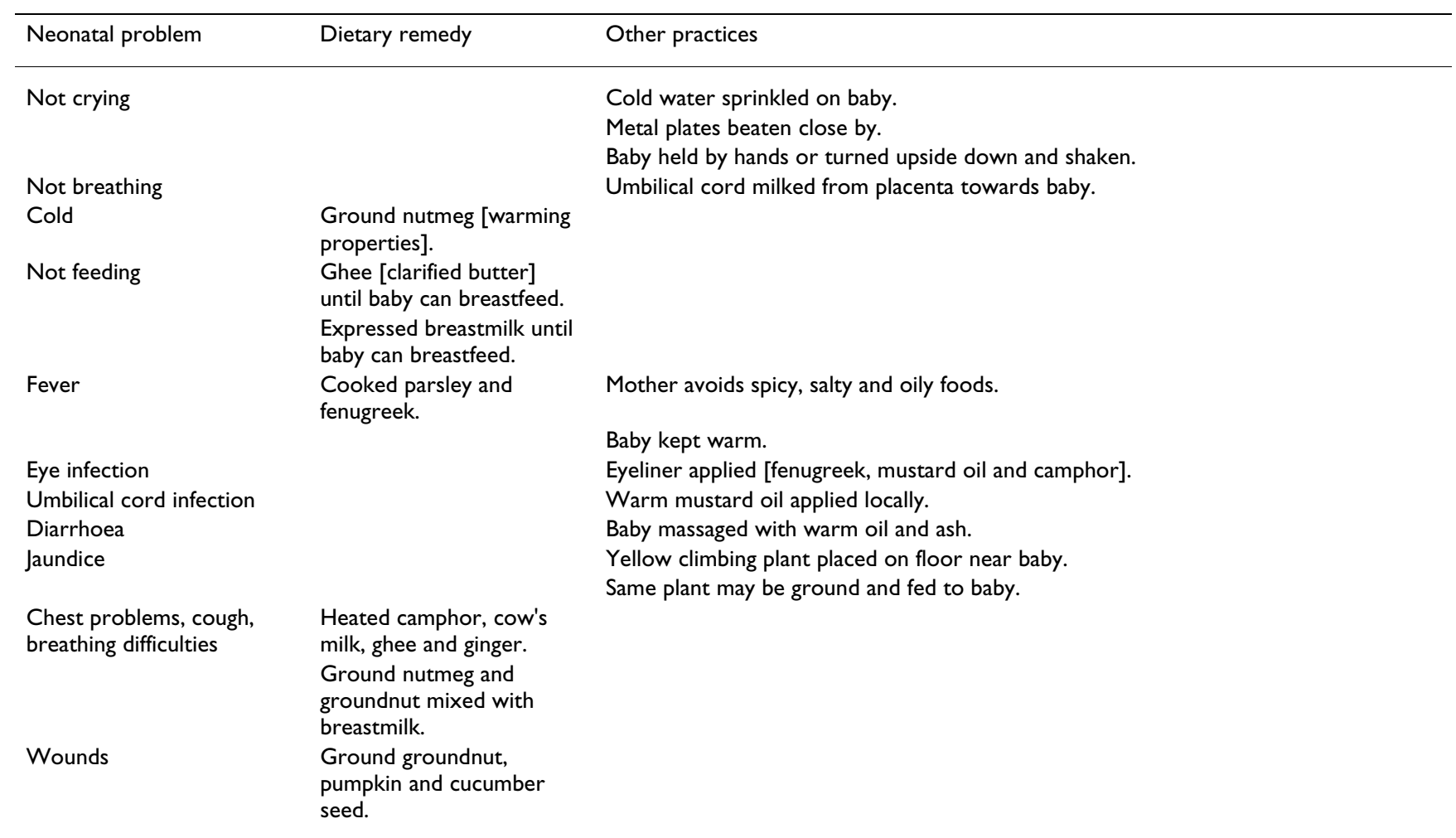


The focus group discussions suggested that, once causality has been decided, and home or traditional remedies do not appear to be working, medicines are often purchased as the first form of allopathic treatment. However, in the survey questionnaire, only three percent of women recalled visiting such a shop. This was probably spurious because respondents did not usually view them as primary consulting facilities, or because they did not think that they represented an appropriate response to the question [ $31 \%$ of women recalled taking allopathic medicine for their problems]. The time from the onset of illness to initial treatment was more than six hours in $31 \%$ of cases.

$12 \%$ of women had visited a government primary health care facility for their illnesses [primary health centre, health post, or sub-health post]. In non-emergency situations, such facilities were not a popular choice. Our informants felt that they could treat only minor ailments, that there was a lack of even basic medicines and that the quality of service was poor. People spoke of being made to wait for treatment if senior staff were present, whereas in their absence they would be seen immediately. In one of the 23 focus group discussions, however, women spoke of the good reputation of a local maternal and child health worker and were enthusiastic about visiting her during pregnancy.

$10 \%$ of women had visited the district hospital, which was seen as a better option than a primary care facility, although attendance depended to a large degree on its proximity. Patterns of referral to the hospital, and from it to tertiary hospitals, were difficult to analyse because formal records were absent. In two case studies, women attending the district hospital were referred on to other hospitals before receiving treatment. Whether this was due to lack of trained staff, lack of medicines or equipment, or a "behaviour of referral" was not clear. Referral patterns also reflected the fact that, for most patients, hospitalisation was not a first choice but rather the outcome of an emergency.

Private clinics were a popular alternative to government services, at least conceptually. Although more expensive, care in the private sector was thought to be better. As a male participant put it: "we go to Hetauda hospital first. If we go to the medical [private clinic] ... some say that it will cost a lot. So we go to the hospital as the cost will be less. But in the hospital the cost can also be high if they prescribe expensive medicines to buy from the medical shop in the bazaar. The only thing that is better in the hospital is that the checkup is free; there are no other facilities, except that in the hospital the sick people can sleep there".

\section{Choice of care}

One of the key findings of the study is the degree of delay in consultation. Of the 760 women who did seek care at a government facility, half took more than 48 hours from the onset of illness to consultation. In all but one case study, an outside carer was only called when the situation became critical, and most informants did not seek care beyond their immediate locality. This is reinforced by the period of seclusion after childbirth [sutkeri], which ends with the naming and cleansing ceremony of nwaran. As a Tamang woman described: "if we have fever after birth, we do not tell anyone for three or four days, then we tell our husband or mother-in-law to bring medicine from the bazaar. If we are not better, the nwaran ceremony may be performed earlier so that we can go to the primary health centre and if necessary to Hetauda Hospital".

Delays in recognition of illness on the part of women, their families and health carers were mentioned throughout the qualitative study. In several case studies, the traditional healer continued to perform his ceremony despite the severity of a newborn infant's condition. However, although traditional healers were the first option for treatment, and their practices might delay referral for allopathic care, the situation may be changing. One older man reported that, "nowadays we still go to see the Dhami Jhankri first, but if a newborn baby does not get better we go to the health post two or three hours later. Previously, we had a stronger belief and we would wait for longer before going to the health post".

The preference for care within the immediate surroundings of the village, and the disinclination by families to act on referral advice, was raised repeatedly in focus groups. Several case studies documented not only resistance to seeking care outside the village on the part of the immediate family, but also advice not to do so from their neighbours. In times of emergency, the preference for care within the environs of the home was overwhelming. This is best illustrated by one of the case studies. A woman was experiencing problems during labour, characterised by the expulsion of parts of what might have been the placenta. After a series of home remedies, the traditional healer was called. About four hours later, with no improvement in the woman's condition, her mother-inlaw sent for the auxiliary health worker from the health post. The health worker came and advised the family to go immediately to the district hospital. His advice was not, however, acted upon, and the woman's husband went to find the traditional birth attendant. She refused to come as by this time night had fallen and her eyesight was weak. An hour later a dead son was delivered.

The reasons for not acting on referral advice varied. In some cases, the severity of the illness militated against 
moving the sick woman or baby, a situation that was exacerbated by the tendency to seek help only at a critical stage. Indeed, where the risk of death was high, respondents felt that it might be better to die at home than outside. In other cases in which illnesses were not critical, perceived expense played a large part in the decision. Men spoke of the need to borrow money for care outside the community and for this reason referral advice was not heeded. Experience of a previous problem did seem, however, to override cost issues and the lack of faith in government health institutions. Women who had had bad experiences in previous pregnancies appeared to be more likely to visit a health facility, in some cases regardless of whether or not they were currently experiencing problems.

\section{Discussion}

Our findings on the recognition of and care for perinatal illness in Nepal, the largest of its kind conducted in a developing country, have implications for the design of Safe Motherhood and newborn care programmes in rural communities. We should be cautious, though, about generalising from the case studies and focus group discussions. The nature of the household, ethnicity of its members, degree of maternal autonomy, economic status, workload and distance to care providers interact to form a matrix unique to each setting. This constitutes one limitation of the study. A second limitation is that it was based on either recall or on hypothesis, rather than on prospective observation of action. We hope to look at this in our prospective follow-up. A mitigating issue is that we were interested in perceived rather than clinical illness, and in community perceptions on the background of which health care behaviour is played out. Thirdly, most of our case studies describe pathways of illness leading to death [there were only four morbidity case studies] and so are not necessarily representative of pathways of illness when the patient recovers. And finally, some discrepancies between survey and qualitative findings, for example in the use of medicine shops, probably reflect a misunderstanding by interviewees of the survey question asked.

\section{Maternity care: pregnancy and vulnerability}

The qualitative findings were notable for a scarcity of information on illness during early pregnancy, related to the tendency to conceal pregnancy, or perhaps to the respondents' remembering more recent, or more major, events. The most common maternal complications in the case studies were prolonged or obstructed labour, postpartum haemorrhage and retained placenta. This is consistent with a national maternal mortality and morbidity study, in which postpartum haemorrhage was the leading cause of maternal death [20]. Likewise, the descriptions of neonatal symptoms and signs - though relatively imprecise - accord with key danger signs identified for essential newborn care [21,22].

The fact that similar patterns of care were found across ethnic groups reflects the national picture $[6,19,23]$. Pregnancy is seen as a normal state, and women work until the onset of labour [24]. They are shy about birth and fear that wider knowledge of their state would bring shame on their husbands' households [25]. We have discussed the ethnography of normal pregnancy elsewhere [14]. Broadly, concealment of pregnancy falls within the ambit of shyness or shame [laaj laagne] [24,26]. Communicating problems during times of pollution, such as menstruation, pregnancy, birth and the postpartum period may compromise the household. During the sutkeri period, mother and baby remain secluded for three to eleven days, and it is not considered favourable to move them until nwaran. Seclusion during this liminal period of vulnerability to spirits and disease is not limited to Nepal $[17,26]$, and has been likened - with particular reference to Brahmin and Chhetri women - to the seclusion undertaken at first menstruation [25].

Home care practices for illness: recognition of abnormality The limited information volunteered on home care practices for illness may imply that they are not seen as treatment, which appears to involve a process of consultation [27]. For those practices that were discussed [presented in Tables 5 and 6], physiological concepts were often explanatory. When illness occurs, it often falls to a mother herself to recognise danger signs. However, her mother-inlaw and husband are usually the bridge between care in the home and care seeking beyond. A mother-in-law's recognition of danger signs and the perceived need for action depend on her own past experience, and it is likely that the construction of normality - the degree of pain tolerable, for example - influences the process of recognition.

\section{Care seeking practices for illness: the ascription of cause}

Once illness is recognised, families prefer to consult a local informal care provider. Our informants spoke of the effort required to access the services of a traditional healer before a mother or her baby died. Discussions about difficulties of access usually refer to government health staff, and it is interesting to see that informal providers may be just as difficult to consult. The implication is that difficulty of access is not necessarily a bar to consultation.

The relationship between the cause of an illness and its symptoms is loose, but the potential for cure follows from a knowledge of causation. The curative process depends on the elimination of a range of possible causes, physical and spiritual, some of which may involve the entire family [27-29], and it is often the work of the traditional healer to tease them out. Some illnesses are well defined and 
their response to allopathic treatment is well known. In such cases, families may bypass the traditional healer and seek allopathic treatment as a first step. It is also possible that an individual's illness has not arisen from transgression, but is simply a matter of fate.

\section{Choice of care: locality and the first delay}

Traditional birth attendants are not commonly called to deliveries. Although a person who serves some of the functions of a birth attendant may be required to cut the umbilical cord in other parts of Nepal and south Asia [23], not one respondent in our study spoke of such a requirement. In rural Makwanpur, a traditional birth attendant has no perceived advantage over a relative. Even if she is called, there are a number of reasons why she may be reluctant to attend. Firstly, the situation has often become critical by the time she arrives and is likely to end in death, for which she might be held responsible. Secondly - and in contrast with a traditional healer - the traditional birth attendant plays no role in the attribution of causality. Thirdly, she has not always been selected for her role on the basis of an interest in fulfilling the it.

The purchase of medications is common and the medicine shop is said to be the usual destination after the traditional healer [30], although this was not confirmed by the survey questionnaire. Our focus group discussions confirmed findings from other studies that medicine shops, in contrast to government health facilities, keep more convenient hours, are found in more convenient locations, minimise waiting time and levy no consulting fees. The social gulf between staff and customers is also narrower [31,32]. The relationship between communities and health post staff has been described in detail elsewhere [33]. It is sufficient to note that the higher the level of health worker, the more likely he or she will be seen as a stranger, a social superior, and one whose otherness is magnified by differences in language, ethnicity and caste.

Referral to hospital is difficult in mountainous terrain and most women in the study area live at least three hours away. Nepal's district hospitals also tend to have a limited capacity to deal with complicated cases. The provision of basic emergency obstetric care in hospital settings has therefore become an important aim of the Safe Motherhood Initiative. The Safe Motherhood framework of three delays is also a useful way of looking at care seeking behaviour [34]. The first delay is in the recognition of illness and the decision to act on it. This is affected by awareness of danger signs, as well as by prevailing attitudes to pregnancy. The second delay is in reaching the source of care, a delay which is affected by geography, transportation and funds. The third delay is in receiving care at an appropriate facility. This is primarily affected by institutional factors.
What is striking about our findings is the importance of the first delay, which itself is made up of a series of significant delays. The decision to seek care outside the household may only be made after a process of elimination of causes, home remedies and observation being part of this process. Issues such as perceived normality, pollution and its transgressive corollaries, shame, the spirit world and multiple causality, affect household decisions. Unfortunately, this curative-diagnostic social process may increase the delay in seeking formal treatment and bring the individual closer to death.

A particular point of delay was the increased tendency to watch and wait in the sutkeri period. The inhibiting effects of sutkeri may extend to the activities of the traditional healer, who may not perform his full ceremony, and in rare cases may not even be called. One result of seclusion practices, whatever their wider implications, is that sick women and their babies face barriers to the recognition of illness and seeking of care outside the household. A range of health care providers is usually available in the community and there appears to be no significant conflict in terms of choice. Rather, the choice of care provider depends upon the nature and timing of the illness and the availability of a trusted informal practitioner.

\section{Conclusions and policy implications}

Our conclusion is that the major obstacles to seeking care are: a limited capacity to recognise danger signs; the need to watch and wait; the inertia of the sutkeri period; and an overwhelming preference to treat illness within the community. All of these fall within the critical first delay in the care seeking model. The actual decision to seek care does not appear to be the pivotal issue. Once a problem has been recognised, senior family members often decide to seek treatment in a timely manner.

Factors influencing the preference for local care include peer pressure, perceived cost [a weighted perception, since visiting the traditional healer can also be costly], distance from a health facility, and reluctance to move a sutkeri and her baby, particularly if they are already thought to be in severe danger and close to death. Traditional healers are more important actors than traditional birth attendants.

What are the policy implications of these findings? Safe Motherhood Programmes, to be successful, must address the three delays which lead to maternal and perinatal mortality. Only strengthening health facilities is unlikely to have an immediate impact on perinatal care practices and care seeking behaviour. Our finding that treatment within the community is considered of great importance strongly argues the case for bringing more trained attendants to community level. Once a problem has been recognised, senior family members often decide to seek 
treatment in a timely manner - suggesting that it is whom care is sought from, which needs to be changed. The roles of the various key actors - mothers-in-law and husbands, village-based health staff, local healers, pharmacies - also need to be addressed if the first and second delays in reaching health facilities are to be shortened. Policymakers might choose one or more of three broad options to address these first delay issues. First, health care workers or volunteers might be trained to give health promotion messages to families. It seems to us that the complexity of the problem, and the limited evidence for the effectiveness of changing behaviour in this way [35] means that such a 'health sector' approach is very unlikely to succeed. Second, a more participatory approach might be developed using a non-health sector worker, such as a trained woman facilitator, to work with women's groups through a community action cycle. The purpose of our ongoing trial is to evaluate the cost-effectiveness of such an approach in changing family behaviour and health outcomes for mothers and newborn infants, and we hope to report the findings by 2004 . A third approach might be to mobilise more direct political support for maternal health through specific policy edicts from the centre. Local political leaders could be held accountable for ensuring certain minimum standards in community participation and health service improvement with regards to care in pregnancy, childbirth and the newborn period, through some kind of national perinatal audit process. They could also assist with the development of emergency financing schemes to help families experiencing obstetric emergencies.

At present, maternal and newborn health remains some way down the policy agenda in Nepal. A huge challenge for health professionals and social scientists is to provide policymakers with options for maternal care which are implementable, scalable and evidence-based at community level. At the same time, programmes to strengthen hospital obstetric care, and to expand access to midwives and trained birth attendants are an urgent priority.

\section{Competing interests}

None of the authors have competing interests.

\section{Authors' contributions}

ST and NM designed the qualitative study, supervised the data collection process and carried out the analysis. DO and NM designed the quantitative study tools and carried out the analysis. NM and DO wrote the first draft of the paper. BS and MM contributed to the design and criticised later drafts of the paper. DM, HS and AC contributed to the design of the study and the supervision of the field programme, and criticised drafts of the paper. NM and AC will act as guarantors for the paper.

\section{Acknowledgements}

The authors wish to thank the many individuals in Makwanpur district who gave their time generously and without complaint, and the field staff of the MIRA Makwanpur Study, without whom this study would not have been possible. We also thank Mr R Rana [Chairperson] and the Makwanpur District Development Committee, and the Village Development Committee members for their active and continuing support; and the MIRA executive committee in Kathmandu. The study was funded by the British Government Department for International Development, UNICEF Nepal, and the Division of Child and Adolescent Health, World Health Organisation.

\section{References}

I. Ministry of Health (Nepal), New ERA and ORC Macro: Nepal demographic and health survey 200I. Calverton, Maryland, Family Health Division, Ministry of Health; New ERA; ORC Macro; 2002.

2. His Majesty's Government/Nepal: Further analysis report on antenatal, delivery, postnatal services, literacy and polio coverage. Nepal multiple indicator surveillance fifth cycle (March-May 1997). Kathmandu, National Planning Commission Secretariat \& Central Bureau of Statistics/UNICEF Nepal; 1998.

3. Hotchkiss DR: Expansion of rural health care and the use of maternal services in Nepal. Health \& Place 200I, 7:39-45.

4. Ratnaike $R, O^{\prime} N$ Neil $P$ and Chynoweth R: Village health workers and malnutrition: a project that failed. World Health Forum I984, 5:316-318.

5. Stone L: Primary health care for whom? Village perspectives from Nepal. Soc Sci Med 1986, 22:293-302.

6. UNICEF Nepal: Health seeking behaviour of women in five safe motherhood districts in Nepal. Kathmandu, United Nations Children's Fund; 1998.

7. Osrin D, Mesko N, Shrestha BP, Shrestha D, Tamang S, Thapa S, Tumbahangphe KM, Shrestha JR, Manandhar MK, Manandhar DS, Standing $\mathrm{H}$ and Costello $\mathrm{A}$ : Reducing childhood mortality in poor countries. Implementing a community-based participatory intervention to improve essential newborn care in rural Nepal. Trans Roy Soc Trop Med Hyg 2003, 97: I-4.

8. Ministry of Finance: Economic survey, fiscal year 2001/2002. Kathmandu, His Majesty's Government, Nepal, Ministry of Finance; 2002.

9. World Bank: World development report 2002. Building institutions for markets. Washington DC, Oxford University Press; 2002.

10. United Nations Development Program: Nepal human development report 200I. Poverty reduction and governance. Kathmandu, United Nations Development Program; 200I.

11. Central Bureau of Statistics: Nepal in figures. Kathmandu, His Majesty's Government, Nepal; 2002.

12. Central Bureau of Statistics: Gender disaggregated indicators. Kathmandu, His Majesty's Government, Nepal, Ministry of Women, Children and Social Welfare; 2002.

13. Osrin D, Tumbahangphe KM, Shrestha D, Mesko N, Shrestha BP, Manandhar MK, Standing H, Manandhar DS and Costello AM de L: Cross sectional, community based study of care of newborn infants in Nepal. Br Med J 2002, 325: 1063.

14. Tamang S, Mesko N, Shrestha BP, Osrin D, Manandhar M, Standing H, Manandhar DS, Shrestha JR and Costello AM: A qualitative description of perinatal care practices in Makwanpur district, Nepal. Contributions to Nepalese Studies 200I, 28: I0-19.

15. Bryman A: Qualitative data analysis. Social research methods Oxford, Oxford University Press; 200I.

16. Reissland $N$ and Burghart $R$ : The quality of a mother's milk and the health of her child: beliefs and practices of the women of Mithila. Soc Sci Med 1988, 27:46I-469.

17. Blanchet $\mathrm{T}$ : Meanings and rituals of birth in rural Bangladesh. Dhaka, University Press Limited; 1984.

18. Goodburn E, Rukhsana $G$ and Chowdhury M: Beliefs and practices regarding delivery and postpartum maternal morbidity in rural Bangladesh. Studies in Family Planning 1995, 26:22-32.

19. Manandhar M: Ethnographic perspectives on obstetric health issues in Nepal: a literature review. London, Options; 2000.

20. Pathak LR, Malla DS, Pradhan A, Rajlawat R, Campbell BB and Kwast B: Maternal mortality and morbidity study. Kathmandu, Family Health Division, Department of Health Services, Ministry of Health, His Majesty's Government of Nepal; 1998. 
21. Ministry of Health: National maternity care guidelines, Nepal. Kathmandu, His Majesty's Government, Nepal, Ministry of Health, Family Health Division; 1996.

22. WHO: Essential newborn care. Report of a technical working group (Trieste, 25-29 April 1994). Geneva, World Health Organization, Division of Reproductive Health (Technical Support); 1996.

23. Levitt M: A systematic study of birth and birth attendants in Nepal. Kathmandu, John Snow International; 1993.

24. March K: Children, childbearing and mothering. Himalayan Research Bulletin 1994, 10:8.

25. Bennett $L$ : Sitting in a cave: an analysis of ritual seclusion at menarche among Brahmin and Chhetris in Nepal. Contributions to Nepalese Studies 1978, 6:32-45.

26. Manandhar M: Birthing practices study. Remote area basic needs project - Bajura. Kathmandu, CARE Nepal; 1999.

27. Jackson J and Jackson-Carroll L: The social significance of routine health behaviour in Tamang daily life. Social Science \& Medicine 1987, 38:999-1010.

28. Scheper-Hughes $N$ and Lock $M$ : The mindful body: a prolegomenon to future work in medical anthropology. Medical Anthropology Quarterly 1987, 1:6-41.

29. Erickson N: What health care when? A literature review and fieldwork study of low-caste women's health care decisionmaking. Kathmandu, Save the Children; 1995.

30. Dhungel B: The qualitative community judgement: the role of the intermediate health practitioners in Nepal's family health services. Anthropology of Nepal: peoples, problems and processes Edited by: Allen M. Kathmandu, Mandala Book Point; 1992.

31. Chalker J, Kapali $M$ and Khadka B: Health post usage in a mountain district in Eastern Nepal. Journal of the Institute of Medicine (Kathmandu) 1990, 1 2:247-257.

32. Kafle K, Madden J, Shrestha A, Karkee S, Das P, Pradhan M and Quick J: Can licensed drug sellers contribute to safe motherhood? A survey of the treatment of pregnancy-related anaemia in Nepal. Social Science \& Medicine 1996, 42: I577-I588.

33. Justice J: Neglect of cultural knowledge in health planning: Nepal's Assistant Nurse-Midwife program. Anthropology and public health: bridging differences in culture and society Edited by: Hahn $R$. New York, Oxford University Press; 1999.

34. Maine D: Safe motherhood programs: options and issues. Centre for Population and Family Health; 1993.

35. Bolam A, Manandhar DS, Shrestha P, Malla K, Ellis M and Costello AM de $L$ : The effects of postnatal health education for mothers on infant care and family planning practices in Nepal: a randomised, controlled trial. British Medical Journal 1998, 134:805-810.

\section{Pre-publication history}

The pre-publication history for this paper can be accessed here:

http://www.biomedcentral.com/1472-698X/3/3/prepub
Publish with Bio Med Central and every scientist can read your work free of charge

"BioMed Central will be the most significant development for disseminating the results of biomedical research in our lifetime. "

Sir Paul Nurse, Cancer Research UK

Your research papers will be:

- available free of charge to the entire biomedical community

- peer reviewed and published immediately upon acceptance

- cited in PubMed and archived on PubMed Central

- yours - you keep the copyright
BioMedcentral 